\title{
A comparison of isocaloric high carbohydrate and high fat test meals in diabetics
}

\author{
D. B. JONES \\ M.R.C.P. \\ P. PATEL \\ S.R.D. \\ P. SLAUGHTER
S.R.N. \\ R. D. CARTER \\ M.I.S.T. \\ J. I. MANN \\ D.M., Ph.D. \\ T. D. R. HOCKADAY \\ F.R.C.P.
}

Diabetes Research Laboratories and Department of Community Medicine and General Practice, University of Oxford, Radcliffe Infirmary, Oxford

\section{Summary}

Ten diabetic patients were given test meals at breakfast and lunch on successive days to compare the acute glycaemic responses to meals either high (65\%) (HC) or extremely low (12\%) in carbohydrate; the latter was very high (71\%) in fat (HF). The meals were isocaloric and fibre content, though higher in $\mathrm{HC}$, was within the range of the average British intake for both diets.

The mean fasting blood glucose levels were similar on the 2 days $(9.8 \mathrm{mmol} / \mathrm{l} ; 9.6 \mathrm{mmol} / \mathrm{l})$ but mean peak post-prandial levels were significantly greater after the $\mathrm{HC}$ meals $(17.7 \mathrm{mmol} / \mathrm{l}$ after breakfast and 14.1 mmol/l after lunch) than after the HF meals (11.7 mmol/litre after breakfast; $P<0.02 ; 8.1 \mathrm{mmol} / 1$ after lunch; $P<0.02)$. Mean blood glucose value for the $6-$ hr study period was significantly higher after the HC meals (14.0 mmol/l) than after the HF meals (9.2 $\mathrm{mmol} / \mathrm{l} ; \mathbf{P}<0.001)$. There was no significant difference in mean fasting, peak or total mean triglyceride level.

In the short term, therefore, meals very low in carbohydrate and high in fat are followed by a lower glycaemic response than meals high in carbohydrate but with only a usual ( $22 \mathrm{~g} /$ day) fibre content. Delayed gastric emptying after HF meals may well contribute to the results but long-term use of such $\mathrm{HF}$ meals is not advised in view of the extremely high fat content.

KEY WORDS: carbohydrate, fat, diabetes, fibre, gastric emptying.

\section{Introduction}

Traditional dietary advice to diabetics centred on caloric restriction, avoidance of simple sugars, reduc- tion of carbohydrate content (around 30\% of total calories) and the recommendation that a high percentage of energy should be derived from fat (Truswell and Thomas, 1975). Such a diet has been challenged recently following the demonstration of improved glycaemic control on diets high in carbohydrate $(60 \%$ of total calories) and in leguminous and cereal fibre (Anderson, 1980; Jenkins et al., 1976; Simpson et al., 1981).

To further define the position, we compared the glycaemic response of meals with the new high carbohydrate content (though here without the usually recommended increase in fibre, which was maintained at the average level of the British diet) (Simpson et al., 1981) with meals extremely low in carbohydrate and very high in fat.

\section{Patients and methods}

Ten diabetic patients (five male, five female) from the Oxford Diabetic Clinic agreed to take part in the study. Seven were insulin treated and three were taking oral hypoglycaemic agents. Their mean age was 59 years and the mean body weight was $70.5 \mathrm{~kg}$. The mean and standard deviation of the ideal body weight was $119 \pm 25 \%$.

The patients were admitted for $48 \mathrm{hr}$ and randomized to receive either the high carbohydrate $(\mathrm{HC})$ or the high fat meals (HF) on the 1st day followed by the alternative meals on the 2 nd day. Blood was taken from a forearm cannula for fasting glucose, insulin, glycosylated haemoglobin and lipids. Further samples were taken at half hourly and hourly intervals for glucose, insulin and triglycerides.

The energy content of the HC meals was distributed as $65 \%$ carbohydrate, $16.5 \%$ fat and $18.5 \%$ 
protein, while the corresponding figures for the HF meals were $12 \%$ carbohydrate, $71 \%$ fat and $17 \%$ protein. The mean fibre content of the meals was $7.7 \mathrm{~g}$ for $\mathrm{HF}$ and $21.8 \mathrm{~g}$ for HC. Mean daily fibre intake of the average British diet is between 10 and $25 \mathrm{~g}$.

The patient's usual caloric intake was calculated from the dietary history obtained by the research dietitian. The meals were prepared to provide a similar energy intake to that which the patient normally consumed at that time, and the calorie content was the same for both days. The mean and standard deviation of the caloric content of the HC and HF meals was $865 \pm 313 \mathrm{kcals}, 40.6 \%$ being given as breakfast and $46.0 \%$ as lunch.

Glucose was measured by a glucose oxidase method on a Pye Unican $\mathrm{Ac}_{1}$ autoanalyzer, glycosylated haemoglobin by an isoelectric focussing technique (Jeppson et al., 1980); cholesterol by a Technicon autoanalyzer using the Libermann Burchard reaction (Huang et al., 1961). Serum triglycerides were measured spectrophotometrically after enzymatic hydrolysis (Wahlefeld, 1974). Insulin was measured by radioimmunoassay after charcoal separation (Albano et al., 1972).

The significance of differences was derived by Students' paired $t$-test.

\section{Results}

The mean fasting blood glucose was not significantly different before the two profiles $(9.8$ and 9.6 $\mathrm{mmol} / \mathrm{l}$ ). The peak post-prandial blood glucose at 90 min was higher after the HC meals both after breakfast $(17.7 \mathrm{mmol} / \mathrm{l})$ and after lunch $(14.1 \mathrm{mmol} / \mathrm{l})$ than after the HF meals (breakfast $11.7 \mathrm{mmol} / 1$, $P<0.02$; lunch $8.1 \mathrm{mmol} / 1 ; P<0.02)$. Mean blood glucose value for the 6-hr study period was significantly higher after the $\mathrm{HC}$ meals $(14.0 \mathrm{mmol} / \mathrm{l})$ than after the HF meals $(9.2 \mathrm{mmol} / \mathrm{l} ; P<0.001)$ (Fig. 1).

Although only three of the patients were not treated with insulin, a significantly higher mean plasma insulin level was obtained during the study period after the $\mathrm{HC}$ meals than after the HF meals. Mean fasting triglyceride levels were similarly raised before the HC $(2.9 \mathrm{mmol} / \mathrm{l})$ and the HF meals $(3.0$ $\mathrm{mmol} / \mathrm{l})$. The normal range of our laboratory is $0.4-1.9 \mathrm{mmol} / 1$. There was no significant difference in mean or peak triglyceride values between the HF and $\mathrm{HC}$ meals. The mean percentage of glycosylated haemoglobin for the ten patients was $10 \cdot 1 \%$. Mean total cholesterol of these patients was $4.5 \mathrm{mmol} / \mathrm{l}$.

\section{Discussion}

The results show that the short-term glycaemic

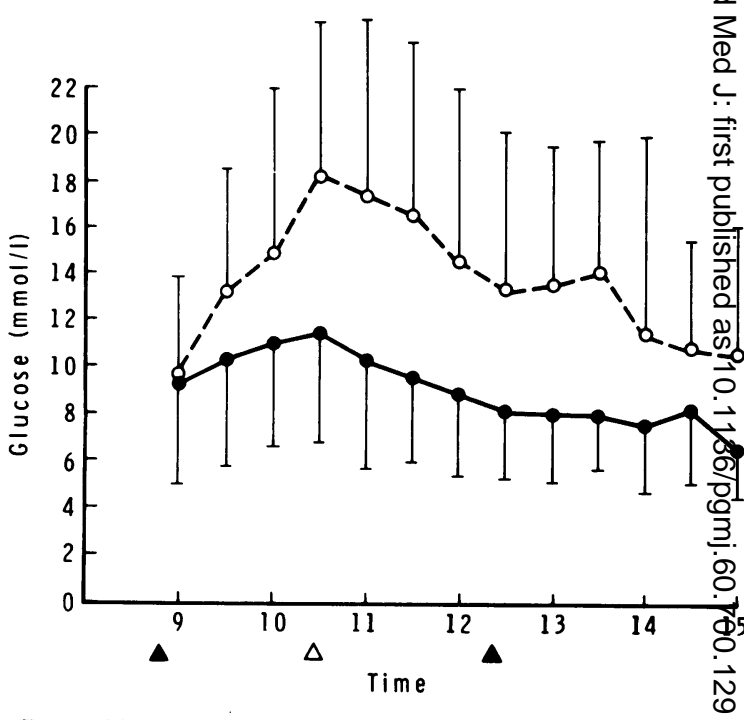

FiG. 1. Blood glucose levels following the high fat (HF) and high carbohydrate (HC) meals (- $)$ HF meal profile; $(\mathrm{O}-1-\mathrm{O})$ HC meal profile. ( $\Delta)$ Breakfast and lunch; $(\Delta)$ Mid morning snack

response to a $\mathrm{HC}$ meal is greater than that after very low carbohydrate, very high fat meal. The fibre. content of the meals was maintained at averges British levels.

Previous work has demonstrated improvementip all aspects of diabetic control on long-term compari son of a high carbohydrate, high fibre diet with medium carbohydrate diet (Simpson et al., 1981/ This is thought to be due predominantly to the effeci of fibre but a recent study suggests that in the longer term, high carbohydrate diets alone offer som\& benefits to diabetics in reducing fasting blood glucose(Simpson et al., 1982). Monnier et al. (1981) have proposed that the minimum daily amount of fibri required to lower blood glucose levels in diabetics $40 \mathrm{~g}$.

Very high fat meals have recently been shown to reduce motility and delay gastric emptying (Evan: Foster and Hardcastle, 1982) and secretion (Roberts 1931; Ivy, 1941) in man, confirming older animad experiments which evoked a gastrointestinal hor? mone, enterogastrone, to explain the effect (Greene gard, Woolley and Ivy, 1944). The lower bloof glucose levels after the HF meals could be at least partly explained on this basis. The plasma insulin results in our patients have not been presented in detail because only three were not insulin treated The fasting plasma triglycerides were elevated priof to the meals but no significant difference was seen $i \frac{0}{1}$ the post-prandial levels between the two profiles.

Within the very considerable limitations of $s \hat{a}$ short-term a study, the glycaemic response to $\mathrm{HC}$ 
meals was greater than that following a very low carbohydrate, high fat meal. Apart from these different contents of the classic dietary components, the results could depend upon either or both of (1) the higher carbohydrate content of the HC diet, in comparison with the very small amount of carbohydrate in the HF diet, or (2) anticipated delayed gastric emptying on such a notably HF diet.

It is unlikely that the modest fibre content of the HC diet, slightly higher than that of the HF diet, would have promoted hyperglycaemia.

The fat content, indeed, is such as to make this HF diet suitable for long-term use and reminds one that glycaemic control is not the only aim of the diabetic diet. The results demonstrate also that meals which are very high in carbohydrate without increase in fibre may produce an adverse increase in blood glucose.

The current definition of dietary fibre (Trowell, 1976), although partly dependent upon digestive function is essentially structural and so doubtless will eventually have to yield to a predominantly functional definition. In some ways this study hints at the overriding importance of gastrointestinal function in determining glycaemic response; delayed gastric emptying from the very high fat content may be compared to a similar effect of viscous fibre (Holt $e t$ al., 1979).

\section{Acknowledgments}

We are grateful to the Simon Broome Heart Research Trust for financial support and to Mrs Anne Reeve for typing the manuscript.

\section{References}

Albano, J.D.M., Ekins, R.P., MarizT, G. \& TURNer, R.C. (1972) A sensitive precise radioimmunoassay of serum insulin relying on charcoal separation of bound and free hormone moieties. Acta Endocrinologica, 70, 457.
ANDERSON, J.W. (1980) High fibre diets for diabetic and hypertriglycerideaemic patients. Canadian Medical Association Journal, 123, 975.

Evans, D.F., Foster, G.E. \& HardCastle, J.D. (1982) Effects of high fat meals on the duration of fasting motility patterns in man. Gut, 23, 915.

Greengard, H., Woolley, J.R. \& IVy, A.C. (1944) Pepsin secretion and enterogastrone. American Journal of Physiology, 141, 281.

Holt, S., Heading, R.C., Carter, D.C., Prescott, L.F. \& TotHILL, P. (1979) Effect of gel fibre on gastric emptying and absorption of glucose and paracetamol. Lancet, i, 636 .

Huang, T.C., Chen, C.P., Wefler, V. \& Raftery, A. (1961) A stable reagent for the Liebermann-Burchard Reaction. Analytical Chemistry, 33, 1405.

IvY, A.C. (1941) The mechanism of gastric secretion. Surgery, 10, 861.

Jenkins, D.J.A., GofF, D.V., LeedS, A.R., Alberti, K.G.M.M., WOLEVER, T.M.S., GASSULl, M.A. \& HoCKADAY, T.D.R. (1976) Unabsorbable carbohydrates and diabetes. Decreased post-prandial hyperglycaemia. Lancet, ii, 172.

JePPSON, J.O., Fizinzen, B. \& GaAl, A.B. (1980) Simplified determination of haemoglobin $\mathrm{Al}_{\mathrm{c}}$ in diabetic patients by use of electrofocussing. In: Electrophoresis 1979. Advanced Methods. Biochemical and Clinical Applications (Ed. B. A. Radola). Walter de Gruyter \& Co. Berlin.

Monnier, L.H., Blotman, M.J., Colette, C., Monierre, M.P. \& MIRONZE, J. (1981) Effects of dietary fibre supplementation in stable and labile insulin dependent diabetics. Diabetologia, 20, 12.

ROBERTS, W.M. (1931) The effect of oils on gastric secretion and motility. Quarterly Journal of Medicine, 24, 133.

Simpson, H.C.R., CARTER, R.D., LOUSLEY, S. \& MANN, J.I. (1982) Digestive carbohydrate - an independent effect on diabetic control on Type II (non-insulin dependent) diabetic patients. Diabetologia, 23, 235.

Simpson, H.C.R., Simpson, R.W., Lousley, S., CARTER, R.D., GeEkIE, M., HockadaY, T.D.R. \& MaNN, J.I. (1981) A high carbohydrate leguminous fibre diet improves all aspects of diabetic control. Lancet, i, 1.

TROWELL, H. (1976) The definition of dietary fibre and the hypothesis for its effect on certain disease states. American Journal of Nutrition, 29, 417.

TRUSWELl, A.S. \& Thomas, B. (1975) Survey of dietary policy in British diabetic clinics. Proceedings of the Nutrition Society, 34, 22.

WAHLEFELD, A.W. (1979) Triglycerides: determination after enzymatic hydrolysis. In: Methods of Enzymatic Analysis. (Ed. H.U. Bergmeyer), 2nd English edn, p. 1836. Academic Press, New York and London.

(Accepted 23 June 1983) 